\title{
Painful blind eye: efficacy of enucleation and evisceration in resolving ocular pain
}

\author{
S D Shah-Desai, A G Tyers, R M Manners
}

\begin{abstract}
Aims-To assess the effectiveness of enucleation or evisceration in relieving pain from painful blind eyes.

Methods-24 patients with intractable ocular pain underwent enucleation or evisceration with or without an orbital implant. Results-Complete pain relief was achieved in all patients at an average time of 3 months (range 1-15 months). Seven patients required further medical or surgical treatment in addition to removal of the globe.

Conclusion-Enucleation and evisceration were effective in relieving ocular pain in all patients with a painful blind eye in our study. However, complications of surgery and orbital implants can cause recurrent pain.

(Br f Ophthalmol 2000;84:437-438)
\end{abstract}

Severe ocular pain is an intolerable condition resulting from various ocular diseases and can be treated with topical steroids, cycloplegics, ocular hypotensives, and bandage contact lenses. Painful blind eyes have been successfully treated with retrobulbar alcohol injection ${ }^{1}$ when the eye looks normal, if the patient is not medically fit for surgery or is opposed to it. However, if the pain is unresponsive to these treatments, especially if the eye is cosmetically disfigured, then enucleation or evisceration may be the treatment of choice. There have been clinicopathological studies of enucleation and evisceration ${ }^{2}$ and reviews of complications of orbital implants. ${ }^{3}$ However few reports have examined whether such surgery resolves pain. ${ }^{4}$

\section{Materials and methods}

The study involved 24 eyes of 24 patients (11 males and 13 females) undergoing enucleation or evisceration, with or without a primary orbital implant for intractable ocular pain. The average patient age was 64 years (range 11-89 years).

The causes of the painful eyes and their visual acuities are shown in Table 1 . The average duration of pain was 59 months (range 1-240 months) during which time various treatments including topical steroids, cycloplegics, ocular lubricants, glaucoma medications, and bandage contact lens had failed to consistently relieve pain.

Past surgical procedures included cataract extraction (nine), cyclocryotherapy (five), retinal detachment surgery (three), trabeculectomy (three), vitrectomy (six), panretinal photocoagulation (one), laser iridotomy (one), corneal graft (one), and cyclodialysis (one).

The decision to perform an enucleation or evisceration with or without an implant, was dependent on the cause of the painful blind eye and patient's and surgeon's preference.

Eight patients underwent enucleation with insertion of an orbital implant made from hydroxyapatite (two), polyethylene (Medpor) (four), and acrylic (two). The implants were wrapped in mersilene mesh sutured with 5-0 Ethibond.

Sixteen patients underwent evisceration, 13 with and three without an implant. Orbital implants used were hydroxyapatite (six),
Eye Department, Salisbury District Hospital, Odstock, Salisbury SP2 8BJ

$S$ D Shah-Desai A G Tyers

Southampton Eye Unit, Southampton General Hospital, Tremona Road, Southampton SO16 6YD

S D Shah-Desai

R M Manners

Correspondence to: Miss R M Manners

Accepted for publication 19 November 1999
Table 1 Patient details

\begin{tabular}{|c|c|c|c|c|c|c|c|}
\hline No & $\begin{array}{l}\text { Age } \\
\text { (years) }\end{array}$ & Cause of painful blind eye & $\begin{array}{l}\text { Visual } \\
\text { acuity }\end{array}$ & $\begin{array}{l}\text { Surgical } \\
\text { procedure }\end{array}$ & Implant & $\begin{array}{l}\text { Cause of postoperative } \\
\text { pain }\end{array}$ & Further treatment \\
\hline 1 & 66 & Glaucoma and uveitis & NPL & enucleation & hydroxyapatite & - & - \\
\hline 2 & 82 & Endophthalmitis & NPL & enucleation & polyethylene & - & - \\
\hline 3 & 77 & Rubeotic glaucoma & NPL & enucleation & acrylic & - & - \\
\hline 4 & 50 & Rubeotic glaucoma & NPL & enucleation & polyethylene & - & - \\
\hline 5 & 67 & Sclerokeratitis & NPL & enucleation & polyethylene & implant exposure & implant removal \\
\hline 6 & 11 & Uveitis and band keratopathy & NPL & enucleation & hydroxyapatite & - & - \\
\hline 7 & 74 & Rubeotic glaucoma & NPL & enucleation & polyethylene & retrobulbar haematoma & resolved at 4 months \\
\hline 8 & 89 & Rubeotic glaucoma & NPL & enucleation & acrylic & prosthesis related & glass eye given \\
\hline 9 & 79 & Glaucoma and band keratopathy & PL & evisceration & acrylic & conjunctival cyst & cyst excised \\
\hline 10 & 41 & Congenital glaucoma & PL & evisceration & hydroxyapatite & - & - \\
\hline 11 & 33 & Trauma & HM & evisceration & hydroxyapatite & - & - \\
\hline 12 & 81 & Glaucoma & PL & evisceration & polyethylene & residual silicone band & removal of band \\
\hline 13 & 66 & Glaucoma & NPL & evisceration & polyethylene & prosthesis related & new artificial eye \\
\hline 14 & 75 & Rubeotic glaucoma & NPL & evisceration & - & - & - \\
\hline 15 & 71 & Trauma & NPL & evisceration & acrylic & - & - \\
\hline 16 & 64 & Rubeotic glaucoma & NPL & evisceration & - & - & - \\
\hline 17 & 84 & Rubeotic glaucoma & NPL & evisceration & acrylic & - & - \\
\hline 18 & 86 & Trauma & NPL & evisceration & hydroxyapatite & - & - \\
\hline 19 & 71 & Rubeotic glaucoma & NPL & evisceration & - & unknown & lubricants \\
\hline 20 & 72 & Glaucoma & NPL & evisceration & acrylic & - & - \\
\hline 21 & 30 & Trauma & NPL & evisceration & hydroxyapatite & - & - \\
\hline 22 & 70 & Uveitis & NPL & evisceration & hydroxyapatite & - & - \\
\hline 23 & 54 & Band keratopathy & NPL & evisceration & polyethylene & - & - \\
\hline 24 & 51 & Rubeotic glaucoma & NPL & evisceration & hydroxyapatite & - & - \\
\hline
\end{tabular}

$\mathrm{NPL}=$ no perception of light $\mathrm{PL}=$ perception of light; $\mathrm{HM}=$ hand movements. 
polyethylene (three), and acrylic (four). The surgical procedure for evisceration included removal of the cornea, placement of orbital implant in the scleral shell, and anterior scleral closure with 6-0 Vicryl. In all procedures, Tenon's and conjunctival closure was layered, wound edges being overlapped and sutured with Vicryl.

The postoperative regimen was chloramphenicol four times daily to the socket for 3-6 weeks, and oral cephalexin $500 \mathrm{mg}$ twice daily for 7 days. Anti-inflammatory medication (diclofenac) was used for pain relief as required. Temporary prosthetic shells were fitted at 4-6 weeks and an artificial eye was in place by 6-12 weeks postoperatively when pain relief was assessed.

\section{Results}

The average duration of follow up was 16 months (range 3-36 months). Ultimate pain relief was achieved in all patients following enucleation or evisceration at an average of 3 months (range 1-5 months). Immediate pain relief (within 6 weeks) was achieved in 17 patients.

Seven patients continued to have pain for an average duration of 8 months (range 4-15 months), requiring further medical or surgical intervention to achieve pain relief. One patient with a pre-enucleation history of sclerokeratitis of unknown aetiology developed a discharging socket and was found to have implant exposure. Further surgery failed to afford conjunctival cover and to relieve pain and the implant was removed 12 months after insertion with complete resolution of the pain and discharge. Postoperative pain secondary to a retrobulbar haematoma in one patient resolved over 4 months. Two patients had prosthesis related pain for 6 months with no evidence of giant papillary conjunctivitis. The pain resolved in one patient on changing to a glass artificial eye and in the other patient with refitting of a new artificial eye. A conjunctival cyst formed in one patient with associated soreness. This was excised 12 months after original surgery with resolution of the discomfort.

A patient who had undergone previous retinal detachment surgery had a foreign body sensation which resolved with removal of a residual piece of silicone band, 4 months after the evisceration. Finally, one patient had ocular discomfort of unknown aetiology which resolved with the use of an ocular lubricant (hypromellose).

\section{Discussion}

When treating painful blind eyes the choice of surgical procedure is dependent on ocular disease and patient and surgeon preference. Enucleation and evisceration are associated with complications including retrobulbar haemorrhage, conjunctival cysts, and wound dehiscence which can cause ocular pain.
Although evisceration is a simpler procedure than enucleation and provides good prosthesis motility, it is theoretically associated with a higher risk of sympathetic ophthalmitis ${ }^{5}$ and in some patients may not relieve ocular pain, since sensory ciliary nerves remain intact and can transmit pain. ${ }^{6}$ Other authors have noted increased pain or ocular discomfort in eviscerated compared with enucleated groups, in the immediate postoperative period. ${ }^{7}$ However, this has not been seen by us in our small series of 16 eviscerations and eight enucleations where both groups had patients with persistent postoperative ocular pain.

In the group of patients who suffered from postoperative ocular pain, six had orbital implants (four polyethylene (two wrapped in mersilene mesh) and two acrylic). One underwent evisceration alone. Implant materials and wrapping can be associated with infection, extrusion, and pain ${ }^{8}$; however, five of the six patients with orbital implants had pain unrelated to this.

Causes for postoperative pain included retrobulbar haematoma (one), conjunctival cyst (one), residual silicone band (one), artificial eye related (two), and of unknown origin (one).

Only one patient had extrusion of orbital implant, which was secondary to conjunctival dehiscence possibly related to their previous chronic sclerokeratitis.

In summary, our experience showed that enucleation and evisceration were both excellent in relieving pain in all of the blind painful eyes in our series. Pain relief occurred over a varying duration, with $71 \%(17 / 24)$ having pain relief within 6 weeks postoperatively and the remaining $29 \%$ (7/24) within 15 months, after further medical or surgical intervention. We recommend that patients who have undergone enucleation or evisceration, with or without an orbital implant and have persistent postoperative pain should be examined thoroughly for an underlying cause of this pain. Effective treatment of this cause is likely to lead to complete relief of pain.

1 Al-Faran MF, Al-Omar OM. Retrobulbar alcohol injection in blind painful eyes. Ann Ophthalmol 1990;22:460-2.

2 Gunalp I, Gunduz K, Ozkan M. Causes of enucleation: a clinicopathological study. Eur F Ophthalmol 1997;7:223-8.

3 Shields CL, Shields JA, De Potter P, et al. Lack of complications in hydroxyapatite orbital implant in 250 consecutive cases. Trans Am Ophthalmol Soc 1993;91:177-89.

4 Bayliss H, Shorr N. Evisceration, enucleation and exenteration. In: McCord CD Jr, ed. Oculoplastic surgery. New York: Raven Press, 1981:313-26.

5 Soll DB. Enucleation and evisceration. In: Duane TD, ed. Clinical ophthalmology. Philadelphia: Harper \& Row, 1982:Vol 5, Chapter 17.

6 Pai-Dei Chen W. Enucleation, evisceration and exenteration. In: McCord CD Jr, Tanenbaum M, Nunery WR, eds. Oculoplastic surgery. 3rd ed. New York: Raven Press, 1995. Chapter 19.

7 Dortzbach RK, Woog JJ. Choice of procedure. Enucleation, evisceration or prosthetic fitting over globes. Ophthalmology 1985;92:1249-55.

8 Fox SA. Ophthalmic plastic surgery. 4th ed. New York: Grune and Stratton, 1970:475-501. 